\title{
The Effects of L2 Experience and Vowel Context on the Perceptual Assimilation of English Fricatives by L2 Thai Learners
}

\author{
Patchanok Kitikanan ${ }^{1}$ \\ ${ }^{1}$ Faculty of Humanities, Naresuan University, Phitsanulok, Thailand \\ Corresponding: Patchanok Kitikanan, Faculty of Humanities, Naresuan University, Phitsanulok, Thailand. Tel: \\ 66-867-281-214. E-mail: nicenanina@gmail.com
}

Received: September 20, 2017

Accepted: November 1, 2017 Online Published: November 3, 2017

doi: $10.5539 /$ elt.v10n $12 \mathrm{p} 72$

URL: http://doi.org/10.5539/elt.v10n12p72

\begin{abstract}
The aim of this study is to investigate the effect of vowel context and language experience in the perceived similarity between L2 English fricatives and Thai sounds. The target English sounds being investigated were the sounds $/ \mathrm{v}, \mathrm{f}, \mathrm{w}, \theta, \mathrm{t}^{\mathrm{h}}, \mathrm{s}, \mathrm{\partial}, \mathrm{d}, \mathrm{z}, \int, \mathrm{t} /$. These sounds were elicited from four native English speakers in words in onset position and followed by three vowel contexts: high, low and back. Subjects were 54 Thai students divided into two groups: English-major and non-English-major. These Thai learners were asked to identify the sounds they heard with the Thai sounds that were closest in their perception. The findings showed that 1) all shared sounds were matched with the same L1 categories, suggesting that the existence of L2 sounds in the L1 sound system supports the perception; 2) most non-shared sounds, except English / $\theta /$ were matched to Thai sounds that were suggested in previous literature; 3 ) the perceived similarity of English $/ \theta /$ and the L1 Thai sounds showed the effect of the vowel context in that this sound was mostly matched with Thai /f/ in the high and low vowel contexts whereas in the back vowel context, it was matched with Thai $/ \mathrm{s} / ; 4$ ) the perceived similarities of both shared and non-shared sounds were affected by vowel context and language experience. The findings of this study shed light on the importance exploring perceived similarities and differences in the phonetic level rather than the phonological one.
\end{abstract}

Keywords: English, fricative, language experience, perceptual assimilation, Thai learners, vowel context

\section{Introduction}

Many studies have shown that when second language (L2) sounds do not exist in the first language (L1), L2 learners have more difficulty learning them than when they exist in the L1 phonological system (e.g., Brière \& Chiachanpong, 1980; Kitikanan \& Al-Tamimi, 2012; Lambacher, Martens, Nelson, \& Berman, 2001). In L2 speech perception research, the fact that L2 learners often have difficulty categorising and discriminating L2 sound contrasts that do not exist in their L1 has been supported by many research findings (Tyler, Best, Goldstein, \& Antoniou, 2014). L2 sounds are believed to be perceived through the L1 sound system (Best \& Tyler, 2007; Escudero, 2005; Flege, 1995; Lado, 1957). Hence the nonnative sound that is different from the native sound causes difficulty as the L2 learners will assimilate the L2 sound to the sound in their L1 sound system (Best \& Tyler, 2007; Escudero, 2005) and the 'mechanism of equivalence classification' (Flege, 1995, p. 239) might inhibit the ability to discriminate L2 sounds. To investigate L2 sound perception, the sound identification (e.g., Bohn \& Flege, 1990; Hattori \& Iverson, 2010) and discrimination tasks (e.g., Guion, Flege, Akahane-Yamada, \& Pruitt, 2000; Lengeris, 2009) are well-known methods. The sound identification task is a task in which the L2 learners identify the sounds in terms of nonnative sound categories whereas the discrimination task is the task in which the L2 learners choose whether two sounds are the same or different.

To make predictions for these two tasks, the perceptual assimilation task is, according to Strange and Shafer (2008), the most valid way to indicate the similarity degree of L1 and L2 sounds as compared to qualitative descriptions of articulatory-phonetic similarities, qualitative perceptual comparisons using narrow transcription of L2 segments, or acoustic comparison of L1 and L2 phones. According to the Perceptual Assimilation Model (PAM) (Best, 1995), the non-native sounds are perceived according to their similarities to or differences from the closest L1 sounds which can be measured by tasks that require L2 listeners to label the non-native sounds and rate them with goodness ratings. Both PAM and the Speech Learning Model (SLM) (Flege, 1995) propose 
that the ability to produce and perceive the L2 sounds is based on the perceived phonetic similarities and discrepancies between the L1 and L2 sound categories.

Many researchers have explored the perceived similarity between L1 and L2 sounds by L2 learners (e.g., Escudero \& Williams, 2011; Holliday, 2016; Strange, Akahane-Yamada, Fitzgerald, \& Kubo, 1996). Their findings showed that L2 learners assimilated the non-native sounds to their closest L1 categories. In addition, the perceived similarity between L1 and L2 sounds is context-dependent as shown by many studies For example, Levy (2009) examined the effects of L2 experience and consonantal context on the perceptual assimilation of Parisian French (PF) /y/ and /œ/ by American English learners. The listeners were divided into three groups: no experience (NoExp), formal instruction (ModExp) and formal-plus-immersion experience (HiExp). One finding showed the effects of $\mathrm{L} 2$ experience in that $\mathrm{PF} / \mathrm{y} /$ was significantly assimilated to $/ \mathrm{j} \mathrm{u} /$ by ModExp group as opposed to by NoExp group and by HiExp group suggesting that learners have different degrees of perceived similarity depending on their L2 experience background. Another example is from the study of Holliday (2016) investigating the perception, identification and discrimination of Korean sibilants $/ \mathrm{s}^{\mathrm{h}} / \mathrm{s}$ and $/ \mathrm{s}^{*} /$ (tense version of Korean /s/) by three groups of native Mandarin speakers: naïve listeners (NM), novice L2 learners (novice MK), advanced L2 learners (advanced MK). These fricatives were followed by one of these vowels: /a, i, u/. The perceptual assimilation findings showed that in the /a/ context, NM group perceived $/ \mathrm{s}^{\mathrm{h}} /$ as aspirated affricate much more often $(61.8 \%)$ than both the novice MK (15\%) and advanced MK groups (13.2\%) suggesting that the perceived similarity is influenced by L2 experience and vowel context. While there are many studies on the perceived similarity of non-native vowels and these two factors, to the best of my knowledge, only the study of Holliday (2016) explored the effects of these two factors on the perceived similarity of non-native fricatives. Apart from that, the fricatives in Holliday's study were Korean. There is no exploration of the effect of these two factors on the perceived similarity of L2 English fricatives yet.

Regarding English and Thai fricatives, English has nine fricatives: /f, v, $\theta$, ठ, s, z, $\int, 3, \mathrm{~h} /$ while Thai has three: /f, $\mathrm{s}, \mathrm{h} /$. Hence /f, $\mathrm{s}, \mathrm{h} /$ are the sounds that exist in both L1 and L2 phonological system (shared sounds) whereas the other six sounds exist only in the L2 sound system (non-shared sounds). While there is a fair number of studies on the production of English fricatives by L2 Thai learners (Brière \& Chiachanpong, 1980; Burkardt, 2008; Chunsuvimol \& Ronakiat, 2000, 2001; Kitikanan, 2016; Kitikanan, Al-Tamimi, \& Khattab, 2015; Richards, 1966; Roengpitya, 2011; Sridhanyarat, 2015, 2017), the study of Pansottee (1992) is the only that was carried out to explore the discrimination of English fricatives and the effect of interstimulus interval on the sound perception of eight-year-old and six-year-old children. The stimuli in her study were three types: a phonemic sound pair (P), in which two sounds exist in L1 and L2 (/f/-/s/), a non-phonemic sound pair (NP), in which neither of the sounds

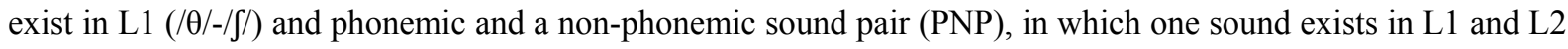
and the other exists in L2 only $\left(/ \mathrm{f} / / / \theta /, / \mathrm{f} /-/ \int /, / \mathrm{s} / / / \theta /\right.$ and $\left./ \mathrm{s} /-/ \delta /\right)$. Her findings showed that older children were better at discriminating sound contrasts than the younger ones suggesting changes in their perceptual development. The findings of this study supports the view that higher language experience is positively correlated to the higher L2 sound discriminating ability. However, her study only investigated the target sound contrasts in /a:/, which might not provide the effect of the vowel context, and it based the hypotheses on the existence of the L2 sound as a phoneme in Thai sound system without exploring the perceived similarity. Hence it is interesting to investigate the perception of English fricative by L2 Thai learners with the perceived similarity in relation to language experience and vowel context to see the extent these two factors affect the L2 fricative perception.

This study is a part of a research project exploring English fricative perception by L2 Thai learners. The target sounds in this study are /f, $v, \theta, \delta, s, z, \int /$. These target fricatives and the sounds that might cause confusion to the L2 learners are in three vowel contexts: high, low, back. The subjects were divided into two groups: English-major and non-English-major. The English-major subjects refers to the English-major students with phonetic training whereas the non-English-major subjects were non-English-major students without phonetic training. All subjects had studied English as a foreign language for almost 20 years; hence this study compares the effect of L2 experience in terms of 'more versus less' (Holliday, 2016, p. 35) rather than 'some versus none' (Holliday, 2016, p. 35). The aim of this study is to investigate the effect of the vowel context and language experience towards the perceived similarity of L2 English fricatives. The results of this study will show that L2 fricatives are not encoded in terms of context-independent phonological categories.

\section{Vowel Context and L2 Speech Perception}

Many studies (e.g. Hardison, 2003; Schmidt, 1996) showed the effect of vowel context over the perception of target L2 sounds. For instance, Schmidt (1996) showed that Korean learners had difficulty discriminating English $/ \mathrm{m}, \mathrm{n}, \mathrm{j}, \mathrm{p}, \mathrm{t}, \mathrm{k}, \mathrm{h} /$ when they were in the back vowel context as compared to the high and low vowel 
contexts. Similarly, Hardison (2003) showed that the perceptual scores of American English $/ \mathrm{A} / \mathrm{and} \mathrm{K} / \mathrm{as}$ perceived by Korean and Japanese learners were lowest in rounded vowels, suggesting negative influence of lip rounding on these two consonants. Lambacher et al. (2001) investigated the identification ability of English voiceless fricatives /f, $\mathrm{s}, \int, \theta, \mathrm{h}$ by Japanese learners in five vowel contexts $/, \varepsilon, \mathrm{a}, \mathrm{o}, \mathrm{u} / \mathrm{T}$ Their findings showed that for $\theta /$, the identification rates were lowest in $/ \varepsilon /$ vowel context. For $\delta$, s/, the most difficult vowel context was $/ 1 /$. For $/ \mathrm{f}, \mathrm{h} /, \mathrm{u} /$ was the most difficult vowel context for this group of learners. These suggest that the vowel context might affect the perceived similarity between L2 sounds and L1 sounds to a different degree.

\section{Language Experience and L2 Speech Perception}

Various studies (e.g. Bohn \& Flege, 1990; Flege, Bohn, \& Jang, 1997; Ingram \& Park, 1997) have shown that L2 experience may increase the ability to discern the differences between L1 and L2 sounds. For example, in the study of Flege et al. (1997), L2 learners of German, Spanish, Mandarin and Korean were divided into experienced and inexperienced groups to investigate their production and perception of English vowels $/$, I, $\varepsilon$, $æ /$ The subjects had lived in the US with different length of residence: the mean of the experienced group was 7.3 years whereas that for the inexperienced group was 0.7 years. The findings showed that the experienced group had higher ability to produce and perceive the English vowels than the inexperienced one. Bohn and Flege (1990) also explored the effect of experience towards these four English vowels /i, I, $\varepsilon, æ$ / as perceived by L2 German learners of English. These subjects were divided into two groups: experienced German and inexperienced German. The mean of duration of experienced listeners in terms of living in the L2 country was 7.5 years whereas that of the inexperienced listeners was 0.6 years. The findings showed that the way the experienced German group distinguished $/ \varepsilon /$ from $/ \mathfrak{x} /$ was similar to that of native English listeners in the way that they relied on spectral cues rather than temporal ones while the inexperienced German group did not.

However, some studies (e.g. Bohn \& Flege, 1990; Flege, Munro, \& Fox, 1994; Munro, 1993) did not show the support of language experience over L2 learning. For example, even though Bohn and Flege (1990) found the positive effect of the language experience towards perceptual discrimination for $/ \varepsilon / / \mathfrak{x} /$ as stated above, they did not find this factor useful in distinguishing $/ \mathrm{i} / \mathrm{/} / \mathrm{/}$. Similarly, Flege et al. (1994) had found no significant effect of language experience in the dissimilarity rating of stimuli of many English and Spanish vowels as perceived by L2 Spanish learners. It seems that the issue of the correlation between L2 experience and English learning is still inconclusive as they might be various internal and external factors at play.

\section{Research Questions and Hypotheses}

In this study, the research questions and hypotheses are as follows: 1) Are shared English sounds assimilated to the same Thai categories? It was hypothesised that the shared sounds would be assimilated to the same Thai categories as they were represented with the same IPA symbols suggesting that they were similar in terms of target-likeness. Hence the L2 Thai learners would select the L1 Thai categories that were represented with the same IPA symbols as the L2 sounds.

2) Are non-shared English sounds assimilated to the closest Thai categories that are shown in previous studies of the production of English fricatives by L2 Thai learners? It was expected that the /v/ would be mostly classified as Thai /w/ (Chunsuvimol \& Ronakiat, 2000, 2001); / $/$ / as Thai /t/ (Brière \& Chiachanpong, 1980; Burkardt, 2008; Richards, 1966), /d/ as Thai /d/ (Brière \& Chiachanpong, 1980; Burkardt, 2008; Richards, 1966), /z/ as Thai /s/ (Brière \& Chiachanpong, 1980; Richards, 1966), /J/ as Thai / $/ 6^{\mathrm{h}} /$ (Brière \& Chiachanpong, 1980) and /t $/$ as Thai $/ \mathbb{t}^{\mathrm{h}} /$ (Kanokpermpoon, 2007).

3) To what does extent perceptual assimilation of shared English sounds by L2 Thai learners vary as a function of language experience and vowel context? It was hypothesised that there would be no effect of language experience nor the vowel context on the perceptual assimilation of shared English sounds by L2 Thai learners as these sounds also occur in Thai sound system, L2 Thai learners, regardless of language experience should benefit from this resulting in the selection of the same phonemic categories as L2 shared sounds across vowel contexts.

4) To what extent does perceptual assimilation of non-shared English sounds by L2 Thai learners vary as a function of language experience and vowel context? For the non-shared L2 sounds, it was predicted that non-English-major learners would assimilate them to the closest L1 categories with higher degree than the experienced ones and there would be the effect of the vowel contexts on these assimilations.

\section{Methodology}

\subsection{Stimuli}

11 target English consonant sounds: /v, f, w, $\theta, \mathrm{t}^{\mathrm{h}}, \mathrm{s}, \mathrm{\partial}, \mathrm{d}, \mathrm{z}, \int, \mathfrak{t} \mathrm{f} /$, i.e. the target fricatives $/ \mathrm{v}, \mathrm{f}, \theta, \mathrm{s}, \mathrm{\partial}, \mathrm{z}, \mathrm{J} /$, and the sounds that showed confusion with English fricatives $/ \mathrm{w}, \mathrm{t}^{\mathrm{h}}, \mathrm{d}, \mathfrak{T} \mathrm{f} /$, were produced in three vowel contexts: 
high, low and back by four female native speakers of British English in real words in carrier phrase "Say...again" to ensure these consonants are not in absolute initial position. Speakers were recorded while producing the stimuli using a high-quality microphone with a frequency response from $15 \mathrm{~Hz}$ to $20 \mathrm{kHz}$. The distance between the microphone and the mouth of the speaker was $5 \mathrm{~cm}$ at a 45-degree angle. The microphone is connected to the recorder (Edirol R-44) and the sound files will be sampled at $44 \mathrm{kHz}$, bin mono channel (16-bit quantisation).

The wordlists were produced by four speakers (five times for each word and each speaker). The total number of English stimuli was 660 (33 words ( 11 consonants $\times 3$ vowels $) \times 4$ speakers $\times 5$ times). Each stimulus was checked for its target-likeness by four English phoneticians. These phoneticians also rated the stimuli for how good it is from (1) 'bad example' to (5) 'very good example' (Guion et al., 2000). To limit the number of stimuli that L2 learners had to listen, three fifth of the tokens for each word that were judged in the range of 4-5 were selected to be used for the experiments. Then after this selection process, the number of English stimuli was 396 ( 11 consonants $\times 3$ vowels $) \times 4$ speakers $\times 3$ times). Before running the perceptual experiments, the stimuli were extracted from the sound files in Praat. As fricatives and stops are difficult to hear on their own, we decided to extract the stimuli from the beginning of the target consonant and the following vowel. The selected portion was windowed by a parabolic function. The intensity was normalised to $65 \mathrm{~dB}$.

\subsection{Subjects}

The participants in this study were divided into two groups: English-major and non-English-major. The English-major group consisted of 28 students majoring in English major and who had passed the phonetics training in the English Phonetics and Phonology module (mean $=19.04$ years, range $=18-20$ years). The non-English-major group consisted of 26 students studying for a non-English-major, i.e. students in Law major who had never been phonetically trained (mean $=19.88$ years, range $=19-20$ years). The difference between these two groups of learners is not only their background in phonetic training but also their English proficiency, i.e. the English-major group had higher level of English proficiency than the non-English-major group as shown in the average English score of English-major students, which was commonly higher than students of other majors. All participants were university students in Thailand. They learned English as EFL, i.e. mainly using English in a classroom context. All listeners reported no hearing nor language impairments, and they were paid for their participation.

\subsection{Procedure}

The participants listened to the stimuli in a quiet computer room at Naresuan University, Thailand. The experiment was run with a script on Praat MFC (Boersma \& Weenink, 2016) on a PC computer. The participants heard the stimuli over the headphone. The instructions on the screen was: 'You will hear a consonant-vowel sequence. Pay attention to the consonant sound and choose the Thai sound that is most similar to the sound you heard. Then rate the similarity of the Thai sound to the sound you heard on a scale from 1 (very different) to 7 (very similar). The number of trials is 684 , and you can break every 50 trials. You can see how far you are from the left top corner of the screen. To continue, click the mouse.' Then they used the mouse to click one from eight L1 sound alternatives: 'ฟ, ว, ต, ท, ส, ด, ช, จ' which represented /f, w, t, t ${ }^{\mathrm{h}}, \mathrm{s}, \mathrm{d}, \mathrm{t}_{6}^{\mathrm{h}}, \mathrm{t}_{6} /$, respectively. To minimise English barrier, the instruction was in their L1. They could hear the sound as many times as they like by clicking 'replay' button. Once they were confident in their answer, they then clicked 'OK' button to move to the next stimulus. Participants heard all 684 stimuli which were 396 English and 288 Thai stimuli of Thai consonant sounds: /f, $\mathrm{w}, \mathrm{t}, \mathrm{t}^{\mathrm{h}}, \mathrm{s}, \mathrm{d}, \mathbb{\mathrm { t }}_{6}^{\mathrm{h}}, \mathrm{f}_{6} /$. The stimuli were fully randomised with $<$ PermuteBalancedNoDoublets $>$ command in the script. The total process lasted for approximately $40-45$ minutes.

\subsection{Data Analysis}

After collecting data, the total number of responses was 21,384 (396 stimuli $\times 54$ listeners). The responses were recorded on Praat and transferred to Excel to encode the observations. As the focus of this experiment is to explore the perception of English consonants through the Thai consonant sounds by L2 Thai learners, the data are shown in percentage of the responses for each Thai sound that were perceived as the most similar to the target English sounds with the means of the goodness of fit. Then following Lengeris (2009) and Guion et al. (2000), to combine the data of the identification and the goodness-of-fit into a single metric, the fit index for each English sound to an L1 consonant category was calculated by multiplying the percentage of the classification for the Thai consonant with 0.01 , and then with the goodness of fit for each response for that L1 consonant category. The interpretation of this fit index is that the higher the fit index, the more perceived similarity between that English sound and its most-frequently-identified L1 category. 
The inferential statistic called linear mixed model (LMM) using the lme4 package (Bates, Maechler, Bolker, \& Walker, 2016) in R statistical software (R Core Team, 2016) was used to generate the statistical findings. The dependent variable was the fit index. The independent variables were vowel context (high, low, back), language experience (English-major, non-English-major) and target English sound ( $\left./ \mathrm{v}, \mathrm{f}, \mathrm{w}, \theta, \mathrm{t}^{\mathrm{h}}, \mathrm{s}, \mathrm{\partial}, \mathrm{d}, \mathrm{z}, \int, \mathfrak{\mathrm { f }} /\right)$. As there was repetition in observations in listeners, the random intercept in this analysis was participant. To select the optimal model, the model with three-way interaction was compared to the model with two-way interaction with anova function. Then the two models were significantly different from one another; hence the model with smaller Akaike Information Criterion (AIC) was chosen (Zhang, 2013). To see the effect of vowel context and language experience, post-hoc tests were performed using the lsmeans package in R statistical software (Lenth, 2014). The interpretation is that the higher fit index, the higher degree of the perceived similarity between the target English sound and the most frequent-identified Thai sound. For shared sound, the higher fit index refers to the greater ease to perceive the L2 sound; on the other hand, for non-shared sound, the higher fit index refers to the greater difficulty to perceive the L2 sound.

\section{Results and Discussion}

In terms of the classifications between L2 English /f, s, v, $\theta, \partial, \mathrm{z}, \int, \mathrm{w}, \mathrm{t}^{\mathrm{h}}, \mathrm{d}, \mathfrak{\mathrm { f }} /$ and the closest Thai categories, the results showed that all shared L2 sounds were classified as the same sounds represented with the same IPA symbols as the closest L1 Thai sounds. This supports our first hypothesis that L2 learners had no difficulty learning the L2 sounds that also occur in their L1 sound system in terms of target-likeness as shown in many studies (e.g., Chunsuvimol \& Ronakiat, 2000; Kitikanan, 2016). This finding suggests that the existence of the sounds in the L1 enhances the perception of the L2 shared sounds, and they suggest that the relationship between production and perception of the shared L2 sounds is one-to-one.

For the non-shared L2 sounds, the findings were as follows: 1) English / $\theta$ / in the high and low vowel contexts was mostly assimilated to Thai /f/ whereas English $/ \theta /$ in the back vowel contexts, and /z/ were mostly classified as Thai $/ \mathrm{s} / ; 2$ ) most English $/ \mathrm{v} /$ tokens were classified as Thai $/ \mathrm{w} / ; 3)$ most English /ठ/ tokens were classified as Thai /d/; 4) most English / $/$ / and $/ \mathfrak{t} /$ were classified as Thai $/ \mathrm{t}_{6} \mathrm{~h} /$. The classifications of English $/ \mathrm{v}, \mathrm{\delta}, \mathrm{z}, \int, \mathfrak{\mathrm { f }} /$ support previous studies on the production of these sounds (Brière \& Chiachanpong, 1980; Burkardt, 2008; Chunsuvimol \& Ronakiat, 2000, 2001; Kanokpermpoon, 2007; Richards, 1966). This suggests that the production and perception are in the same direction, and it also supports that the L2 speech production is based on perception (Flege, 1995).

The findings of English $/ \theta$ / in all vowel contexts were the only one that does not support the findings of previous production studies showing that this sound was mostly articulated as /t/ (Burkardt, 2008; Kitikanan, 2016). This might be due to different type of task between those studies and this study that those studies used the production task whereas this study used the perception task. The perceptual assimilation findings of English $/ \theta /$ showed the effect of the vowel context as English $/ \theta$ / in the back vowel context was mostly classified as Thai /s/ whereas English $/ \theta /$ in the high and low vowel contexts was mostly classified as Thai /f/. The inconsistency of the production and perception of English / $\theta /$ by L2 Thai learners might suggest that the perception and production in L2 sound is not one-to-one relationship, and the perception does not always precede the production as suggested by Flege (1995). The finding that English $/ \theta /$ was differently matched with Thai sounds in different vowel contexts also suggests the effect of the vowel context over the L2 sound perceptual assimilation across the learners' language experience. The assimilation of English $/ \theta /$ in the back vowel context that was different from the other two vowel contexts might be because the back vowel is produced with lip rounding and the tongue is back which might change the production of English $/ \theta /$ into slightly more backward and this articulatory feature is important cue for L2 Thai learners resulting in the selection of English / $\theta /$ as Thai $/ \mathrm{s} /$ instead of Thai /f/ as in the other two vowel contexts. The classification of English $/ \theta /$ as Thai /f/ in the high and low vowel contexts is not surprising as shown in many studies on the learning of L2 English / $\theta$ / that it is produced as /f/, such as in the L2 production of this sound by Chinese speakers (Deterding, 2006). Similarly the classification of English $/ \theta /$ as Thai /s/ in the low vowel context is not surprising either as shown in the production of English $/ \theta /$ by L2 learners of other linguistic backgrounds, such as German and European-French learners of English that often produce /s/ for English / $\theta /$ (Hanulikova \& Weber, 2010). The /s/ and /f/ are close sounds to English / $/$ / as /f/ is phonetically similar to $/ \theta /$ whereas $/ \mathrm{s} /$ is phonologically similar to /s/ (Wester, Gilbers, \& Lowie, 2007). Most findings of non-shared L2 sounds, except English /8/ support our second hypothesis that non-shared English sounds would be assimilated to the closest Thai categories as shown in the previous studies of the production of English fricatives by $\mathrm{L} 2$ Thai learners 
Table 1. Percentages of the categorisation of English fricatives into Thai consonant sounds with the mean of goodness of fit rating (1: very different, 7: very similar), the mean fit index for each English fricative and the fit index based on LMM classified according to vowel context and language experience. The number of categorisations by English-major students is 336 whereas those by non-English-major students is 312

\begin{tabular}{|c|c|c|c|c|c|c|c|}
\hline $\begin{array}{l}\text { Target } \\
\text { L2 } \\
\text { sounds }\end{array}$ & Vowel & Experience & $\begin{array}{l}\text { L1 closet } \\
\text { consonant }\end{array}$ & $\begin{array}{l}\text { Percentage of } \\
\text { identification }\end{array}$ & $\begin{array}{l}\text { Mean goodness } \\
\text { of fit rating }\end{array}$ & $\begin{array}{l}\text { Fit index } \\
\text { (Mean) }\end{array}$ & $\begin{array}{l}\text { Fit index } \\
\text { (from } \\
\text { LMM) }\end{array}$ \\
\hline \multirow[t]{6}{*}{ Eng /f/ } & & Eng & \multirow[t]{6}{*}{$/ \mathrm{f} /$} & 78.27 & 4.57 & 3.58 & 3.55 \\
\hline & \multirow[t]{2}{*}{ High } & Non-Eng & & 79.49 & 4.85 & 3.86 & 3.88 \\
\hline & & Eng & & 84.23 & 4.99 & 4.20 & 4.18 \\
\hline & \multirow[t]{2}{*}{ Low } & Non-Eng & & 86.54 & 5.19 & 4.49 & 4.48 \\
\hline & & Eng & & 95.24 & 4.90 & 4.67 & 4.66 \\
\hline & Back & Non-Eng & & 96.47 & 5.21 & 5.03 & 5.02 \\
\hline \multirow[t]{6}{*}{ Eng /s/ } & \multirow{3}{*}{ High } & Eng & \multirow[t]{6}{*}{$/ \mathrm{s} /$} & 99.11 & 5.17 & 5.12 & 5.12 \\
\hline & & Non-Eng & & 97.76 & 5.58 & 5.45 & 5.45 \\
\hline & & Eng & & 99.11 & 4.93 & 4.89 & 4.88 \\
\hline & \multirow[t]{2}{*}{ Low } & Non-Eng & & 97.76 & 5.07 & 4.96 & 4.94 \\
\hline & & Eng & & 99.40 & 4.66 & 4.63 & 4.63 \\
\hline & Back & Non-Eng & & 92.95 & 4.93 & 4.58 & 4.58 \\
\hline \multirow[t]{6}{*}{ Eng /v/ } & \multirow{3}{*}{ High } & Eng & \multirow[t]{6}{*}{$/ \mathrm{w} /$} & 78.57 & 3.57 & 2.81 & 3.54 \\
\hline & & Non-Eng & & 84.94 & 4.43 & 3.76 & 4.45 \\
\hline & & Eng & & 66.96 & 3.92 & 2.63 & 3.84 \\
\hline & \multirow[t]{2}{*}{ Low } & Non-Eng & & 67.31 & 4.67 & 3.14 & 4.60 \\
\hline & & Eng & & 68.45 & 3.25 & 2.22 & 3.23 \\
\hline & Back & Non-Eng & & 62.18 & 4.37 & 2.72 & 4.30 \\
\hline \multirow[t]{6}{*}{ Eng $/ \theta /$} & \multirow{3}{*}{ High } & Eng & $/ \mathrm{f} /$ & 68.75 & 4.53 & 3.11 & 3.07 \\
\hline & & Non-Eng & & 70.83 & 4.83 & 3.42 & 3.48 \\
\hline & & Eng & & 72.32 & 4.58 & 3.31 & 3.26 \\
\hline & \multirow[t]{2}{*}{ Low } & Non-Eng & & 77.56 & 4.93 & 3.82 & 3.83 \\
\hline & & Eng & $/ \mathrm{s} /$ & 73.51 & 3.51 & 2.58 & 2.55 \\
\hline & Back & Non-Eng & & 81.41 & 4.71 & 3.83 & 3.84 \\
\hline \multirow[t]{6}{*}{ Eng /ð/ } & \multirow{3}{*}{ High } & Eng & $/ \mathrm{d} /$ & 63.39 & 3.72 & 2.36 & 2.30 \\
\hline & & Non-Eng & & 44.55 & 4.25 & 1.89 & 1.67 \\
\hline & & Eng & & 44.05 & 3.36 & 1.48 & 1.43 \\
\hline & Low & Non-Eng & & 38.14 & 4.71 & 1.80 & 1.83 \\
\hline & \multirow[b]{2}{*}{ Back } & Eng & & 65.18 & 2.63 & 1.71 & 1.72 \\
\hline & & Non-Eng & & 36.22 & 3.81 & 1.38 & 1.21 \\
\hline \multirow[t]{5}{*}{ Eng /z/ } & \multirow{3}{*}{ High } & Eng & $/ \mathrm{s} /$ & 97.32 & 3.35 & 3.26 & 3.26 \\
\hline & & Non-Eng & & 96.15 & 4.53 & 4.36 & 4.34 \\
\hline & & Eng & & 91.37 & 3.86 & 3.53 & 3.53 \\
\hline & Low & Non-Eng & & 94.55 & 4.72 & 4.46 & 4.46 \\
\hline & Back & Eng & & 96.43 & 3.71 & 3.58 & 3.58 \\
\hline
\end{tabular}




\begin{tabular}{|c|c|c|c|c|c|c|c|}
\hline & & Non-Eng & & 91.35 & 4.85 & 4.43 & 4.38 \\
\hline \multirow[t]{6}{*}{ Eng / $/$} & \multirow[b]{2}{*}{ High } & Eng & \multirow[t]{6}{*}{$/ \mathrm{t}^{\mathrm{h}} /$} & 100.00 & 5.13 & 5.13 & 5.13 \\
\hline & & Non-Eng & & 96.15 & 5.54 & 5.33 & 5.31 \\
\hline & \multirow[b]{2}{*}{ Low } & Eng & & 98.51 & 4.91 & 4.84 & 4.83 \\
\hline & & Non-Eng & & 91.03 & 5.41 & 4.92 & 4.88 \\
\hline & \multirow[b]{2}{*}{ Back } & Eng & & 98.81 & 4.64 & 4.58 & 4.57 \\
\hline & & Non-Eng & & 95.51 & 5.54 & 5.29 & 5.25 \\
\hline \multirow[t]{6}{*}{ Eng $/ \mathrm{w} /$} & \multirow{3}{*}{ High } & Eng & \multirow[t]{6}{*}{$/ \mathrm{w} /$} & 99.70 & 5.20 & 5.18 & 5.19 \\
\hline & & Non-Eng & & 99.04 & 5.34 & 5.29 & 5.28 \\
\hline & & Eng & & 100.00 & 5.70 & 5.70 & 5.70 \\
\hline & Low & Non-Eng & & 99.68 & 5.72 & 5.70 & 5.69 \\
\hline & \multirow[b]{2}{*}{ Back } & Eng & & 100.00 & 4.75 & 4.75 & 4.75 \\
\hline & & Non-Eng & & 99.68 & 5.17 & 5.15 & 5.15 \\
\hline \multirow[t]{6}{*}{ Eng $/ \mathrm{t}^{\mathrm{h}} /$} & \multirow[b]{2}{*}{ High } & Eng & \multirow[t]{6}{*}{$/ \mathrm{t}^{\mathrm{h}} /$} & 88.69 & 5.24 & 4.65 & 4.63 \\
\hline & & Non-Eng & & 88.46 & 5.49 & 4.86 & 4.84 \\
\hline & \multirow[b]{2}{*}{ Low } & Eng & & 80.95 & 4.96 & 4.02 & 4.00 \\
\hline & & Non-Eng & & 78.53 & 5.17 & 4.06 & 4.01 \\
\hline & \multirow[b]{2}{*}{ Back } & Eng & & 97.92 & 4.98 & 4.88 & 4.87 \\
\hline & & Non-Eng & & 97.44 & 5.14 & 5.01 & 5.00 \\
\hline \multirow[t]{6}{*}{ Eng /d/ } & \multirow[b]{2}{*}{ High } & Eng & \multirow[t]{6}{*}{$/ \mathrm{d} /$} & 97.62 & 5.22 & 5.10 & 5.09 \\
\hline & & Non-Eng & & 94.55 & 5.71 & 5.40 & 5.38 \\
\hline & \multirow[b]{2}{*}{ Low } & Eng & & 90.48 & 5.13 & 4.64 & 4.59 \\
\hline & & Non-Eng & & 76.60 & 5.26 & 4.03 & 3.99 \\
\hline & \multirow[b]{2}{*}{ Back } & Eng & & 99.11 & 4.72 & 4.68 & 4.67 \\
\hline & & Non-Eng & & 96.47 & 5.30 & 5.11 & 5.10 \\
\hline \multirow[t]{6}{*}{ Eng $/ \mathfrak{t} /$} & \multirow{3}{*}{ High } & Eng & & 99.11 & 5.14 & 5.09 & 5.10 \\
\hline & & Non-Eng & & 94.55 & 5.46 & 5.16 & 5.12 \\
\hline & & Eng & & 98.51 & 5.22 & 5.14 & 5.13 \\
\hline & \multirow[t]{2}{*}{ Low } & Non-Eng & & 96.47 & 5.50 & 5.31 & 5.25 \\
\hline & & Eng & & 100.00 & 4.85 & 4.85 & 4.85 \\
\hline & Back & Non-Eng & $/ \mathrm{t}^{\mathrm{h}} /$ & 97.12 & 5.39 & 5.23 & 5.21 \\
\hline
\end{tabular}

Findings from pairwise comparisons show that the fit indexes were significantly higher in the English-major group than in the non-English-major group when English /d/ was perceived as Thai /d/ in the low vowel context $(b=0.59, S E=0.26, d f=77.50, t=2.26, p<0.05)$ and when English $/ \delta /$ was perceived as Thai $/ \mathrm{d} /$ in the high vowel context $(b=0.62, S E=0.28, d f=93.98, t=2.26, p<0.05)$. These findings might sound like they do not support the L2 phonological theorists (e.g., Best \& Strange, 1992; Flege, 1995) proposing that L2 experience might enhance the ability to distinguish the differences between non-native and native sounds. In fact, in might be that Thai /d/ is very similar in terms of perceptual, acoustic and articulatory to English /d/ especially in the low vowel context as opposed to the other two vowel contexts. The reason why the English-major group identified English / $/$ / as more similar to Thai /d/ in the high vowel context than the non-English-major group might be because of the similarity between these two sounds as shown in the realisation of /d/ that is often used for the production of English /ठ/ in the speech of native speakers of English (Labov, 1969). 
The fit indexes were significantly higher in non-English-major group as compared to English-major group when English $/ \mathrm{z} /$ was perceived as Thai $/ \mathrm{s} /$ in all vowel contexts, when English $/ \mathrm{v} /$ was perceived as Thai $/ \mathrm{w} /$ in all vowel contexts $(b=-0.93, S E=0.26, d f=74.58, t=-3.57, p<0.01$ for $/ \mathrm{z} /$ in the low vowel context; $b=-1.08$, $S E=0.26, d f=73.70, t=-4.16, p<0.01 \mathrm{for} / \mathrm{z} /$ in the high vowel context; $b=-0.80, S E=0.26, d f=74.40, t=$ $-3.09, p<0.01$ for $/ \mathrm{z} /$ in the back vowel context; $b=-0.76, S E=0.27, d f=83.80, t=-2.85, p<0.05$ for $/ \mathrm{v} /$ in the low vowel context; $b=-0.91, S E=0.26, d f=77.81, t=-3.47, p<0.01$ for $/ \mathrm{v} /$ in the high vowel context; $b=$ $-1.07, S E=0.27, d f=84.85, t=-3.98, p<0.01$ for $/ \mathrm{v} /$ in the back vowel context). The finding relating to the perceived similarity between English $/ \mathrm{z} /$ and Thai $/ \mathrm{s} /$ being higher in non-English-major rather than English-major groups supports many studies (Brière \& Chiachanpong, 1980; Kitikanan, 2016; Richards, 1966) that suggest that this sound is difficult for L2 Thai learners, yet it suggests that the learning of English $/ \mathrm{z} /$ is possible with phonetic training. For the finding of the perceived similarity of English $/ \mathrm{v} /$ as Thai $/ \mathrm{w} /$ that was higher in non-English-major group rather than English-major one also supports many studies (Chunsuvimol \& Ronakiat, 2000, 2001; Kitikanan, 2016; Richards, 1966) that this sound is difficult to learn for Thai learners, and it suggests the improvement of the learning with phonetic training.

The same pattern was found when English $/ /$ / was perceived as Thai $/ \mathbb{t}_{6} \mathrm{~h} /$ in the back vowel context $(b=-0.67$, $S E=0.26, d f=73.62, t=-2.60, p<0.05)$, when English $/ \theta /$ was perceived as Thai $/ \mathrm{s} /$ in the back vowel context $(b=-1.29, S E=0.26, d f=79.34, t=-4.89, p<0.01)$ and when English $/ \theta /$ was perceived as Thai /f/ in the low vowel context $(b=-0.56, S E=0.26, d f=80.28, t=-2.13, p<0.05)$. The finding that the fit indexes were significantly higher in non-English-major group as compared to English-major group when English /S/ was perceived as Thai $/ \mathrm{t}^{\mathrm{h}} /$ in the back vowel context. This finding supports the study of Kitikanan (2016) showing the positive relationship between the back vowel context as opposed to the front low and front high vowel contexts, and the target-like realisation of English $/ / /$ produced by L2 Thai learners. This might be because the subjects in Kitikanan's study were L2 Thai learners in the L2 country who had more exposure to English and used more English in their daily lives. Hence our finding suggests the requirement of the training for English / $/$ in the back vowel context to be able to distinguish English $/ \int /$ from Thai $/ \pi_{6}^{\mathrm{h}} /$. The findings that the fit indexes were significantly higher in non-English-major group as compared to English-major group when English $/ \theta$ / was perceived as Thai $/ \mathrm{s} /$ in the back vowel context and English $/ \theta /$ was perceived as Thai /f/ in the low vowel context. While there was no effects of vowel context in Kitikanan's production study (2016), the effect of language experience was found in interaction with the vowel context in this study. This suggests that the variables that play role in production and perception might be different, and the ability of L2 Thai learners to distinguish English $/ \theta /$ from Thai $/ \mathrm{s} /$ in the back vowel context and Thai /f/ in the low vowel context can be improved with phonetic training. In addition, no effect of experience was found for the remaining results ( $p>$ 0.05 for all other contrasts).

Regarding the hypotheses, the third hypothesis predicted that there would be no effect of language experience and vowel context on the perceptual assimilation of shared English sounds. This hypothesis is supported except in the perceived similarity of English /d/ as Thai /d/ in the low vowel context. The last hypothesis predicted that non-English-major learners would assimilate non-shared English sounds to the closest L1 categories with higher degree than the English-major ones and there would be the effect of the vowel contexts on these assimilations. This hypothesis is partially supported in the perceived similarity of English $/ \mathrm{z} /$ as Thai $/ \mathrm{s} /$ and English $/ \mathrm{v} /$ as Thai $/ \mathrm{w} /$ across vowel contexts, English $/ \theta /$ as Thai /f/ in the low vowel context, English $/ \theta /$ as Thai $/ \mathrm{s} /$ and English $/ \mathrm{f} /$ as Thai $/ \mathbb{t}_{6} \mathrm{~h} /$ in the back vowel context as in these contexts, the non-English-major learners assimilated non-shared English sounds to the closest L1 sounds than the English-major ones. The effect of the vowel

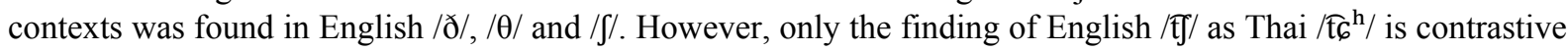
to this hypothesis as there was no effect of both factors on its perceived similarity.

\section{Conclusion}

Results of this study contribute to previous studies showing that the perceived similarity of L2 sounds to the L1 categories does not occur in a context-independent manner (e.g., Levy, 2009; Strange, Akahane-Yamada, Kubo, Trent, \& Nishi, 2001). Even in the shared L2 sounds where each of them was classified as the sounds represented with the same IPA symbols, the degree of the perceived similarities in each pair is affected by the vowel context and language experience. In the non-shared L2 sounds, the effects of these two factors also appear in the findings. These findings support both PAM and SLM in that the details in the phonetic level of these similarities and differences are needed before making precise predictions regarding cross-linguistic perceptual assimilation patterns.

The findings of the perceived similarity of the L2 English fricatives in this study imply that the vowel context and language experience should be taken into account before designing a perceptual training of the L2 sounds. 
For example, in the back vowel context, English $/ \mathrm{J} /$ was perceived to be more similar to Thai $/ \mathbb{t}_{6}^{\mathrm{h}} /$ in the non-English-major group as compared to in the English-major group while in the other two vowel contexts, no significant difference was found in the perceived similarity of these two sounds in two groups. This suggests that in the training of English $/ \mathrm{S} /$, the non-English-major group should include more practice on the dissimilarities between English $/ / /$ and Thai $/ \mathrm{t}_{6}^{\mathrm{h}} /$ in the back vowel context than the English-major group. In the other two vowel contexts, these two groups of learners might receive the same amount of practice for English $/ \mathrm{g} /$ and Thai $/ \mathrm{t}_{6} \mathrm{~h} /$. Previous studies showed that there is some training for the L2 Thai learners to learn L2 English fricatives both in terms of production (Imamesup, 2012; Isarankura, 2015) and perception (Lerdpaisalwong, 2015); nevertheless none of these studies have taken the vowel context and language experience into account. Future project of training the English fricatives for L2 Thai learners might create the training that provides variability of the target sounds as well as fits the language experience of the L2 learners and the vowel contexts.

\section{Acknowledgement}

This work was financially supported by Naresuan University (R2560C126). In addition, I would like to express my sincere gratitude to Dr. Ghada Khattab for her encouragement and insightful comments for this study.

\section{References}

Bates, D., Maechler, M., Bolker, B., \& Walker, S. (2016). lme4: Linear mixed-effects models using Eigen and S4. Retrieved from http://CRAN.R-project.org/package $=1 \mathrm{me} 4$

Best, C. T. (1995). A direct realist perspective on cross-language speech perception. In W. Strange (Ed.), Speech perception and linguistic experience: Issues in cross-language research (pp. 171-204). Timonium, MD: York Press.

Best, C. T., \& Strange, W. (1992). Effects of phonological and phonetic factors on cross-language perception of approximants. Journal of Phonetics, 20(3), 305-330.

Best, C. T., \& Tyler, M. D. (2007). Nonnative and second-language speech perception: Commonalities and complementarities. In M. J. Munro, \& O.-S. Bohn (Eds.), Second language speech learning: The role of language experience in speech perception and production (pp. 13-34). Amsterdam: John Benjamins. https://doi.org/10.1075/11lt.17.07bes

Boersma, P., \& Weenink, D. (2016). Praat, a system for doing phonetics by computer (Version Version 6.0.19). Retrieved from http://www.praat.org/

Bohn, O.-S., \& Flege, J. E. (1990). Interlingual identification and the role of foreign language experience in L2 vowel perception. Applied Psycholinguistics, 11(03), 303-328. https://doi.org/10.1017/S0142716400008912

Brière, E. n. J., \& Chiachanpong, C. S. (1980). An investigation of Thai interference in selected American English phonemes. Poznań Studies in Contemporary Linguistics, 11, 101-117.

Burkardt, B. A. (2008). Acquisition sequence of the English interdental fricatives by Thai ESL learners. (Master's Thesis), Southern Illinois University at Carbondale, Illinois.

Chunsuvimol, B., \& Ronakiat, N. (2000). Stylistic variation of [f] and [v] in the English of Thai students. Research Report.

Chunsuvimol, B., \& Ronakiat, N. (2001). (v) is really a problem sound for Thai speakers. Thammasat Review, 2, 84-95.

Deterding, D. (2006). The pronunciation of English by speakers from China. English World-Wide, 27(2), 175-198. https://doi.org/10.1075/eww.27.2.04det

Escudero, P. (2005). Linguistic perception and second language acquisition: explaining the attainment of optimal phonological categorization. (Doctoral dissertation), Utrecht University.

Escudero, P., \& Williams, D. (2011). Perceptual assimilation of Dutch vowels by Peruvian Spanish listeners. The Journal of the Acoustical Society of America, 129(1), EL1-EL7. http://dx.doi.org/10.1121/1.3525042

Flege, J. E. (1995). Second language speech learning: Theory, findings, and problems. Speech perception and linguistic experience: Issues in cross-language research, 233-277.

Flege, J. E., Bohn, O.-S., \& Jang, S. (1997). Effects of experience on non-native speakers' production and perception of English vowels. Journal of Phonetics, 25(4), 437-470. https://doi.org/10.1006/jpho.1997.0052 
Flege, J. E., Munro, M. J., \& Fox, R. A. (1994). Auditory and categorical effects on cross - language vowel perception. The Journal of the Acoustical Society of America, 95(6), 3623-3641. https://doi.org/10.1121/1.409931

Guion, S. G., Flege, J. E., Akahane-Yamada, R., \& Pruitt, J. C. (2000). An investigation of current models of second language speech perception: The case of Japanese adults' perception of English consonants. The Journal of the Acoustical Society of America, 107(5), 2711-2724. https://doi.org/10.1121/1.428657

Hanulikova, A., \& Weber, A. (2010). Production of English interdental fricatives by Dutch, German, and English speakers. Paper presented at the New Sounds 2010: Sixth International Symposium on the Acquisition of Second Language Speech.

Hardison, D. M. (2003). Acquisition of second-language speech: Effects of visual cues, context, and talker variability. Applied Psycholinguistics, 24, 495-522. https://doi.org/10.1017/S0142716403000250

Hattori, K., \& Iverson, P. (2010). Examination of the relationship between L2 perception and production: an investigation of English/r/-/1/perception and production by adult Japanese speakers. Paper presented at the Interspeech Workshop on Second Language Studies: Acquisition, Learning, Education and Technology.

Holliday, J. J. (2016). Second Language Experience Can Hinder the Discrimination of Nonnative Phonological Contrasts. Phonetica, 73(1), 33-51. http://doi.org/10.1159/000443312

Imamesup, A. (2012). The study of the efectiveness of Audioarticulation model in improving Thai Learners' pronunciation of fricative sounds. (Master dissertation), Srinakharinwirot University.

Ingram, J. C., \& Park, S.-G. (1997). Cross-language vowel perception and production by Japanese and Korean learners of English. Journal of Phonetics, 25(3), 343-370. https://doi.org/10.1006/jpho.1997.0048

Isarankura, S. (2015). Using the Audio-Articulation Method to Improve EFL Learners' Pronunciation of the English /v/ Sound. Thammasat Review, 18(2), 116-137. http://doi.org/14456/tureview.2015.7

Kanokpermpoon, M. (2007). Thai and English consonantal sounds: a problem or a potential for EFL learning? ABAC Journal, 27(1).

Kitikanan, P. (2016). L2 English fricative production by Thai learners. (PhD thesis), Newcastle University, Newcastle.

Kitikanan, P., \& Al-Tamimi, J. (2012). The earliest stage of voiceless fricative acquisition among Thai learners of Mandarin Chinese. ARECLS, 9, 91-114.

Kitikanan, P., Al-Tamimi, J., \& Khattab, G. (2015). An acoustic investigation of the production of English /s/ by L2 Thai learners. Paper presented at the 18th International Congress of Phonetic Sciences (ICPhS2015), Glasgow, Scotland.

Labov, W. (1969). A Study of Non-Standard English. Washington, D.C.: Center for Applied Linguistics.

Lado, R. (1957). Linguistics Across Cultures. Ann Arbor, Mich.: Univeristy of Michigan Press.

Lambacher, S., Martens, W., Nelson, B., \& Berman, J. (2001). Identification of English voiceless fricatives by Japanese listeners: The influence of vowel context on sensitivity and response bias. Acoustical Science and Technology, 22(5), 334-343. https://doi.org/10.1250/ast.22.334

Lengeris, A. (2009). Perceptual assimilation and L2 learning: Evidence from the perception of Southern British English vowels by native speakers of Greek and Japanese. Phonetica, 66(3), 169-187. http://doi.org/10.1159/000235659

Lenth, R. V. (2014). lsmeans: Least-Squares Means. Retrieved from http://CRAN.R-project.org/package=lsmeans

Lerdpaisalwong, S. (2015). Perception Training of Thai Learners: American English Consonants and Vowels. (Doctoral dissertation), The University of Wisconsin-Milwaukee. Retrieved from $\mathrm{http}: / / \mathrm{dc}$.uwm.edu/cgi/viewcontent.cgi?article $=2014 \&$ context=etd\&sei-redir $=1 \&$ referer $=\mathrm{https} \% 3 \mathrm{~A} \% 2 \mathrm{~F} \% 2$ Fscholar.google.co.th\%2Fscholar\%3Fhl\%3Den\%26as_sdt\%3D0\%252C5\%26q\%3DPerception\%2BTrainin g\%2Bof\%2BThai\%2BLearners\%253A\%2BAmerican\%2BEnglish\%2BConsonants\%2Band\%2BVowels\%2 6btnG\%3D\#search=\%22Perception\%20Training\%20Thai\%20Learners\%3A\%20American\%20English\%20 Consonants $\% 20$ Vowels $\% 22$ 
Levy, E. S. (2009). Language experience and consonantal context effects on perceptual assimilation of French vowels by American-English learners of French. The Journal of the Acoustical Society of America, 125(2), 1138-1152. http://doi.org/10.1121/1.3050256

Munro, M. J. (1993). Productions of English vowels by native speakers of Arabic: Acoustic measurements and accentedness ratings. Language and Speech, 36(1), 39-66. https://doi.org/10.1177/002383099303600103

Pansottee, S. (1992). Fricative perception in six and eight year old Thai children. (Master's Thesis), Chulalongkorn University, Bangkok.

R Core Team. (2016). R: A language and environment for statistical computing. Vienna, Austria. Retrieved from http://www.R-project.org/

Richards, J. (1966). Pronunciation features of Thai speakers of English. Paper presented at the Conference of the Linguistic society of New Zealand, Auckland, New Zealand.

Roengpitya, R. (2011). An acoustic study of Englsih and Thai fricatives produced by Thai speakers. Paper presented at the 17th International Congress of Phonetic Sciences (ICPhS XVII), Hong Kong, China.

Schmidt, A. M. (1996). Cross-language identification of consonants. Part 1. Korean perception of English. Journal of Acoustical Society of America, 99(5), 3201-3211. https://doi.org/10.1121/1.414804

Sridhanyarat, K. (2015). Acquisition of English fricatives by Thai university students. Man in India (Special Issue: Researches in Education and Social Sciences), 95, 635-647.

Sridhanyarat, K. (2017). The Acquisition of L2 Fricatives in Thai Learners' Interlanguage. 3L: Language, Linguistics, Literature ${ }^{\circledR}, 23(1)$. http://doi.org/10.17576/3L-2017-2301-02

Strange, W., Akahane-Yamada, R., Fitzgerald, B. H., \& Kubo, R. (1996). Perceptual assimilation of American English vowels by Japanese listeners. Paper presented at the Spoken Language, 1996. ICSLP 96. Proceedings., Fourth International Conference on. https://doi.org/10.1109/ICSLP.1996.607307

Strange, W., Akahane-Yamada, R., Kubo, R., Trent, S. A., \& Nishi, K. (2001). Effects of consonantal context on perceptual assimilation of American English vowels by Japanese listeners. The Journal of the Acoustical Society of America, 109(4), 1691-1704. https://doi.org/10.1121/1.1353594

Strange, W., \& Shafer, V. L. (2008). Speech perception in second language learners: The re-education of selective perception. In J. G. H. Edwards, \& M. L. Zampini (Eds.), Phonology and Second Language Acquisition (pp. 153-192). Amsterdam: John Benjamins Publishing Company. https://doi.org/10.1075/sibil.36.09str

Tyler, M. D., Best, C. T., Goldstein, L. M., \& Antoniou, M. (2014). Investigating the role of articulatory organs and perceptual assimilation of native and non - native fricative place contrasts. Developmental psychobiology, 56(2), 210-227. http://doi.org/10.1002/dev.21195

Wester, F., Gilbers, D., \& Lowie, W. (2007). Substitution of dental fricatives in English by Dutch L2 speakers. Language Sciences, 29(2), 477-491. http://doi.org/10.1016/j.langsci.2006.12.029

Zhang, X. (2013). Foreign language listening anxiety and listening performance: Conceptualizations and causal relationships. System, 41(1), 164-177. https://doi.org/10.1016/j.system.2013.01.004

\section{Copyrights}

Copyright for this article is retained by the author(s), with first publication rights granted to the journal.

This is an open-access article distributed under the terms and conditions of the Creative Commons Attribution license (http://creativecommons.org/licenses/by/4.0/). 